\title{
Transitions Within MD-PhD Programs: Reassurance for Students
}

\author{
Stephen Chrzanowski ${ }^{1}$ (D)
}

Published online: 18 September 2017

(C) International Association of Medical Science Educators 2017

As quickly as it started, it ended. Just one year prior, when the $\mathrm{PhD}$ concluded, I was briskly and seemingly underprepared, ventured back into the clinical world of medicine as an M3. My "doctor" title granted from the PhD felt meaningless in the clinic. The experiences volunteering at free clinics and numerous shadowing opportunities integrated over the prior four years during my research training acutely evaded my mind on a daily basis. My expertise at animal surgeries and operating various sophisticated laboratory machinery poorly translated to better history taking, physical exam skills, and assessment and plans. To describe my state of mind as "petrified" was a gross understatement during this metamorphosis. Annually, MD-PhD trainees briskly undergo transition from the comfortable research training years to the seemingly chaotic clinical realm, feeling underprepared, overwhelmed, and anxious. Without consensus to provide adequate preparation for the optimal management of the transition to clinic, institutions worldwide continue to attempt to assist MD-PhD trainees through these training points without consensus on which mechanisms may be most effective.

My own state of shock was not unique, as the population of $\mathrm{MD}-\mathrm{PhD}$ students in America continues to rise annually, greater numbers of $\mathrm{MD}-\mathrm{PhD}$ trainees undergo the transition from laboratory to clinic [1]. Currently, average training time to graduation for $\mathrm{MD}-\mathrm{PhD}$ students continue to increase, from 6.5 years in 1980 to approximately 8.0 years today [2]. Currently, most programs are organized in a 2-4-2 manner: two years of didactical clinical education, four years of

Stephen Chrzanowski

stevechrzanowski@ufl.edu

1 Department of Physiology and Functional Genomics, University of Florida, Gainesville, FL, USA graduate research culminating in the $\mathrm{PhD}$ degree, followed by a return to clinic to complete the final two years of clinical clerkships [3]. MD-PhD students face unique challenges throughout our training, most notably through the number of abrupt transitions that are undergone into graduate school from the confines of medical school, typically between the M2 and M3 years, and more dauntingly, back into the clinic after completing graduate training [4-8]. Furthermore, as a minority of the overall medical and graduate colleges, MD$\mathrm{PhD}$ students remain a forgotten population during the training years [9]. Other concerns that MD-PhD programs face include the increasing non-traditional nature of many $\mathrm{PhD}$ studies and a paucity of representation of minorities and women in MD-PhD programs, further perpetuating the stresses faced by these MD-PhD students $[10,11]$. The transition from classroom to clinic has been identified as the most stressful period of medical education by MD-specific students [12, 13]. The transition from lab to clinic includes differences in functional pace, teaching style, learning approaches, and overall culture, further amplifying the stresses associated with the changes experience. MD-specific medical students have described the experience as anxiety provoking due to the abrupt nature of the transition, the lack of clear expectations, and the need for better preparedness. This stress is amplified even greater for MD- $\mathrm{PhD}$ students who have just experienced a prolonged vacancy from the clinic [14]. In fact, at the University of California-San Diego (UCSD), $75 \%$ of Medical Scientist Training Program (MSTP) students stated that they had no clinical experience in two years prior to reentry to the M3 year [15]. Despite the best intentions and efforts, reintroduction to the clinic is frequently only bluntly accomplished by a "trial by fire" experience, and I hope through this perspective, to give fellow MD-PhD students a sense of reassurance that their return to the clinic will be successful.

During the research training years, several opportunities are available to $\mathrm{MD}-\mathrm{PhD}$ students to bolster their opportunity 
to succeed upon returning to the clinic. Most primitively, the most important aspect to maintain during the research years, even at a minimal level, is clinical exposure. This can be accomplished through a number of mechanisms, including but not limited to volunteering at local free clinics, shadowing or working with assigned clinical mentors, conducting clinical research that requires collaboration with clinicians, or through formal clinical preceptorship programs [15-18]. Volunteering at free clinics remains a common trend among medical schools, providing opportunities for students to volunteer, gain medical knowledge, and provide much needed community service frequently to a less fortunate population [19-22]. Furthermore, volunteering at free clinics has demonstrated a number of positive benefits for medical students, including maintained empathy during the M3 and M4 years and improved attitudes towards indigent populations and maintaining an overall sense of well-being [19, 20]. Additionally, clinical mentors are widely implemented throughout medical schools and remain a logical solution to provide opportunities for clinical exposure during research years [23]. Appropriate clinical mentors are the ones who recently graduated MD-PhD scholars, who themselves are familiar with the difficulties encountered in MD-PhD training programs. Thirdly, depending on the type of research one may be performing, he or she may have opportunities to work with clinicians pertinent to their research, providing further opportunities specific to their clinical interests. Lastly, clinical preceptorship and reimmersion programs are becoming more frequently utilized as a formal reintroduction to clinical medicine at the conclusion of the $\mathrm{PhD}[15,16]$. Recently, Bills et al. demonstrated that MSTP students who undergo a formal clinical preceptorship program have statistically comparable grades to MD-specific students upon reentry to the clinic [16]. In the UCSD study, 95\% of MSTP students reported that the reimmersion program was a productive use of time and should be recommended to all future students [15]. Unfortunately, these options are frequently institution specific and not always available to individuals at all institutions. That said, even a basal commitment to remaining clinically active during the research years is imperative to maintain clinical adequacies. Besides achieving comparable grades to traditional MD students and measuring the clinical skill assessments following reentry programs, the mitigation of stress through these transition periods has only been supported through anecdotal evidence rather than formalized investigation [14-17].

Upon reentry to the clinic, while uncomfortable at first, the formally structured environment of the clinic counter intuitively provides a very safe learning opportunity for students, as students are able to "make mistakes" under the protective barrier of the rest of the clinical team. The journey through the clinical clerkships is a rollercoaster, filled with peaks and troughs. Due to the frenetic pace of the hospital, one cannot perseverate too long on the negative experiences, always forced to quickly reflect and move forward to address new problems.

In conclusion, all MD-PhD students survive the transition back to clinical medicine. Despite my efforts to maintain clinical skills during the research years, my feeling of inadequate clinical preparation was unfortunately not unique. The clinical years offer an intimacy into the lives of patients during their most fragile and vulnerable times, forging a sacred communion that few occupations have the privilege to experience. Ultimately, the clinical training diversifies and broadens the scope of training received by MD-PhD trainees, contributing to the unique comprehensive breadth of knowledge. To MD$\mathrm{PhD}$ students, the anxiety and uncertainty of the foreign clinical medicine world evolve into a thrilling experience, with new learning opportunities and memorable adventures everyday.

\section{References}

1. Table B-1: Total Enrollment by U.S. Medical School and Sex Enrollment, Graduates, and MD/PhD Data - FACTS: Applicants, Matriculants, Enrollment, Graduates, $\mathrm{MD} / \mathrm{PhD}$, and Residency Applicants Data - Data and Analysis - AAMC. Available at: https://www.aamc.org/data/facts/enrollmentgraduate/158808/totalenrollment-by-medical-school-by-sex.html. (Accessed: 20th June 2017).

2. Brass LF, et al. Are MD-PhD programs meeting their goals? An analysis of career choices made by graduates of $24 \mathrm{MD}-\mathrm{PhD}$ programs. Acad Med J Assoc Am Med Coll. 2010;85:692-701.

3. Dyrbye LN, Rohren C, Tiegs R. An MD-PhD re-entry curriculum. Med Educ. 2004;38:548-9.

4. Goldstein MJ, Kohrt HE. What happened to the concept of the physician-scientist? Acad Med J Assoc Am Med Coll. 2012;87: 132-3.

5. Eley DS, Wilkinson D. Additional perspectives on transforming science into medicine. Acad Med J Assoc Am Med Coll. 2012;87:1310; author reply 1311-1313.

6. Roberts SF, Fischhoff MA, Sakowski SA, Feldman EL. Perspective: transforming science into medicine: how clinicianscientists can build bridges across research's 'valley of death'. Acad Med J Assoc Am Med Coll. 2012;87:266-70.

7. Stacpoole PW, et al. Teaching hypothesis-oriented thinking to medical students: the University of Florida's clinical investigation program. Acad Med J Assoc Am Med Coll. 2001;76:287-92.

8. Schafer AI. The vanishing physician-scientist? Transl Res J Lab Clin Med. 2010;155:1-2.

9. Vallerand IA. Burnout among $\mathrm{MD} / \mathrm{PhD}$ trainees: the forgotten subgroup. Acad Med J Assoc Am Med Coll. 2017;92:906.

10. Zogg CK. Who is a medical scientist training program student? Interviewing for an $\mathrm{MD}-\mathrm{PhD}$ as a 'nontraditional' researcher. Acad Med J Assoc Am Med Coll. 2017;92:732.

11. Gotian R, Raymore JC, Rhooms S-K, Liberman L, Andersen OS. Gateways to the laboratory: how an MD-PhD program increased the number of minority physician-scientists. Acad Med J Assoc Am Med Coll. 2017;92:628-34.

12. Prince KJAH, Boshuizen HPA, van der Vleuten CPM, Scherpbier AJJA. Students' opinions about their preparation for clinical practice. Med Educ. 2005;39:704-12. 
13. Radcliffe C, Lester H. Perceived stress during undergraduate medical training: a qualitative study. Med Educ. 2003;37:32-8.

14. Teunissen PW, Westerman M. Opportunity or threat: the ambiguity of the consequences of transitions in medical education. Med Educ. 2011;45:51-9.

15. Goldberg C, Insel PA. Preparing MD-PhD students for clinical rotations: navigating the interface between $\mathrm{PhD}$ and $\mathrm{MD}$ training. Acad Med J Assoc Am Med Coll. 2013;88:745-7.

16. Bills JL, Davidson M, Dermody TS. Effectiveness of a clinical intervention for $\mathrm{MD} / \mathrm{PhD}$ students re-entering medical school. Teach Learn Med. 2013;25:77-83.

17. Ciampa EJ, et al. A workshop on leadership for $\mathrm{MD} / \mathrm{PhD}$ students. Med Educ Online. 2011;16

18. Sanders JL. A student's perspective on reaching full potential in academic medicine. Acad Med J Assoc Am Med Coll. 2012;87: 1478.
19. Smith SD, Johnson ML, Rodriguez N, Moutier C, Beck E. Medical student perceptions of the educational value of a student-run free clinic. Fam Med. 2012;44:646-9.

20. Modi A, Fascelli M, Daitch Z, Hojat M. Evaluating the relationship between participation in student-run free clinics and changes in empathy in medical students. J Prim Care Community Health. 2017;8:122-6.

21. Davenport BA. Witnessing and the medical gaze: how medical students learn to see at a free clinic for the homeless. Med Anthropol Q. 2000;14:310-27.

22. Beck E. The UCSD student-run free clinic project: transdisciplinary health professional education. J Health Care Poor Underserved. 2005;16:207-19.

23. Sambunjak D, Straus SE, Marusić A. Mentoring in academic medicine: a systematic review. JAMA. 2006;296:1103-15. 